\title{
A mathematical model for crashing projects by considering time, cost, quality and risk
}

\author{
Amin Mahmoudi ${ }^{\mathrm{a}}$ and Mohammad Reza Feylizadeh ${ }^{\mathrm{a}}$
}

${ }^{a}$ Department of Industrial Engineering, Shiraz Branch, Islamic Azad University, Shiraz, Iran

\begin{tabular}{l}
\hline C H R O N I C L E \\
\hline Article history: \\
Received: March 5, 2017 \\
Received in revised format: April \\
16, 2017 \\
Accepted: July 15, 2017 \\
Available online: \\
July 15, 2017 \\
\hline Keywords: \\
Crashing \\
Cost of conformance \\
Cost of non-conformance \\
Costs of quality \\
Risk management \\
Integer programming \\
\hline
\end{tabular}

\section{A B S T R A C T}

\begin{abstract}
Employers are looking for reducing execution time and maintaining the quality of the projects that are the main objective of the projects. In this article, we focus on crashing projects by considering different factors such as cost, time, quality and risk. For the proposed integer linear model, cost of conformance and cost of non-conformance are considered as parts of the costs of quality of deliverables in projects. The cost of conformance consists of the costs of training the project team, inspection and test of deliverables. The cost of non-conformance also includes costs of rework and scrap. Project risk management is one of the important aspects of the projects. The present study also considers the impact of risks, which is highly applicable in projects with a high level of uncertainty. Results are presented using integer programming approach with the aim of minimizing the costs of the project.
\end{abstract}

\section{Introduction}

Nowadays, project management is used as a significant skill in many industries. For this reason, the knowledge of projects and their management are of high importance. The term "project" designates a temporary effort with a starting point and a unique product or a service as an ending point. Projects are mainly characterized by uniqueness and temporary. According to the Project Management Body of Knowledge, there are different constraints in projects including time, cost, scope, quality, resources and risks (Project Management Institute, 2013). Fig. 1 shows project constraints. In each project, one of these constraints can be superior compared with another constraint. Project manager's ability should include balancing the constraints in a way that all the project objectives are fulfilled. Critical Path Method (CPM) is a reliable method that has been invented and it can be employed for creating a scheduling plan in every type of project. In this method, the first step is the estimation of activity duration. The next step is measuring project duration by delineating Activity on Arrow (AOA) network (Project Management Institute., 2011).

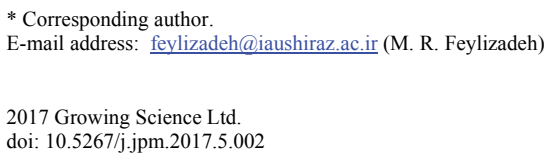




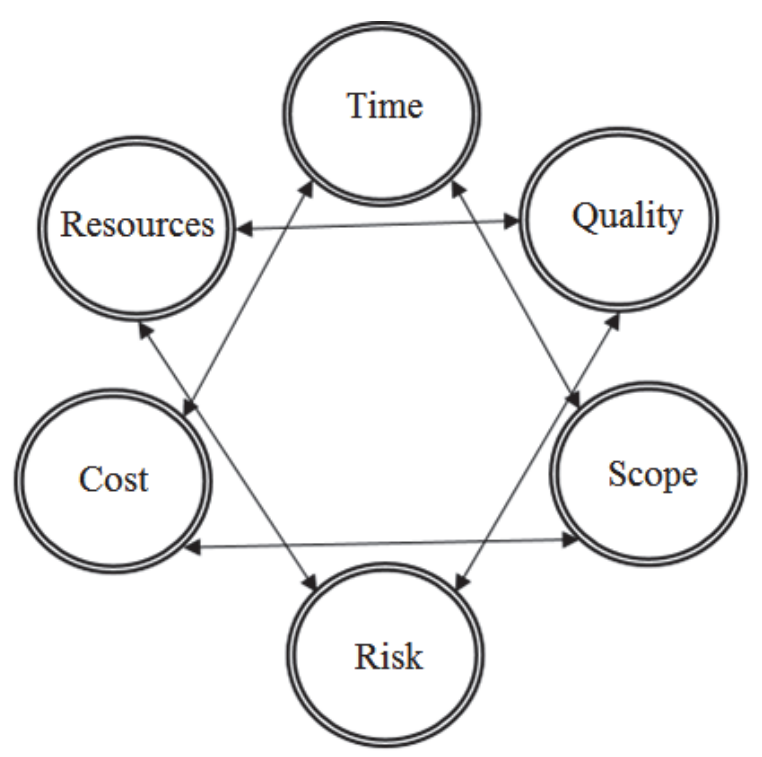

Fig. 1. Project constraints

After the exploration of the project team, usually the estimated time in CPM network is more than the project time constraint. Based on the Project Management Body of Knowledge, crashing, is the key technique for reducing project duration. Crashing designates adding resources to the project critical activities to reduce activity duration. Project scope is considered as fixed in using crashing technique and efforts are made to balance cost and time. The crashing technique has been employed in the present study by considering the objectives of time, cost, quality and risk. The costs paid for the quality are categorized into two types (Kiran, 2017):

\section{The Cost of Conformance.}

\section{The Cost of Non-conformance.}

Cost of conformance is the total cost of ensuring that a deliverable is of good quality. The cost of training the project team, inspection and test costs belong to this type of cost. The costs of non-conformance designate the rework costs that are employed for correcting the deliverables. If the cost of conformance is considered in projects, the cost of non-conformance will be decreased in the future. Table 1 shows quality costs.

\section{Table 1}

Cost of quality (Project Management Institute, 2013)

\begin{tabular}{lc}
\hline \multicolumn{1}{c}{ Cost of Conformance } & \multicolumn{1}{c}{ Cost of Non-conformance } \\
\hline Prevention Costs: & Internal Failure Costs: \\
$>$ Training & $>$ Rework \\
$>$ Document processes & \\
$>$ Equipment & \\
$>$ Time to do it right & External Failure Costs: \\
Appraisal Costs: & $>$ Liabilities \\
$>$ Testing & $>$ Warranty work \\
$>$ Destructive testing loss & $>$ Lost business \\
\hline Inspections &
\end{tabular}

Project risk management is not an optional process. Rather, it is an essential process for project success. Project risk management pays attention to assess the uncertainties in the estimates and assumptions projects. Thus, project risk management depends on other areas of knowledge of project management 
like time and costs management. Risks designate events or conditions that can positively or negatively impact project objectives. The risks that negatively impact project objectives are referred to as "threat". For instance, facing inflation and the increase of the price of the raw materials can be viewed as threats to the project. In contrast, the risks that positively impact the project objectives are referred to as “'opportunities"' (Project Management Institute, 2009). The more credit allocation for a project, can be viewed as an opportunity, for instance. As understood from the above-mentioned definition, risks are characterized by uncertainties and they impact project objectives. "Probability" designates the level of risk uncertainty and "impact" designates the level of effect of risk on the project objectives (Lester, 2017). If the severity of the risk impact is calculated based on cost, then, by having the probability of occurrence, the risk expected monetary value can be calculated using the Eq. (1):

$$
\text { Expected Monetary Value }=\text { Risk impact } \times \text { Risk probability. }
$$

During crashing a project, risk probability can be reduced or increased. This is a significant issue that needs to be considered during project crashing. In the mathematical model introduced in this study, the costs of project quality, opportunity, and threats during crashing are taken into consideration. The authors try to make the proposed model close to the reality and apply it so that the project managers' needs are met.

\section{Literature review}

It was in the later 1950s that time-cost trade off attracted the attention of project managers. The reduction of the project time, taking into account the factors that affect the project implementation, has always been a challenge to the project managers. Multiple methods have been introduced for the optimization of time-cost trade off employed several mathematical models, heuristic and meta-heuristic algorithms. Kelly (1961) was a researcher who introduced a linear mathematical model for project planning. This model was mainly focused on the time and cost of project activities. In another study, Feng (1997) employed the genetic algorithm in order to obtain absolute optimal answers. The main problem was that the time and cost uncertainties were not considered in the study. In an effort to solve this problem, Feng et al. (2000) studied time and cost in an atmosphere of trade off uncertainty. Sakellaropoulos and Chassiakos (2004), in order to present a solution using realistic project features such as the interrelationship of the activities and external constraints, introduced a time-cost integer linear programming model, in a bid to minimize cost. This method had many applications in engineering projects. Leu et al. (2005) presented a model that, using integer linear programming, would choose favourable resources, among the resources existing for the activities, to optimize time-cost in construction projects. Only time and cost were taken into consideration in all these models. As time goes by quality was viewed as a significant factor in project quality contracts, researchers tried to take into consideration quality as the third criteria. Babu and Suresh (1996) introduced a linear programming model by taking quality into consideration. In their opinion, project quality changes with project crashing. They determined bounds for cost and time and thereby found the optimal value for quality. This model was attractive since it was very simple. Khang and Myint (1999) presented a case study in a cement factory in Thailand in which they used the model proposed by Bau and Suresh. This model maintained some issues in terms of quality. El-Rayes and Kandil (2005) proposed a model that took into consideration the three criteria of cost, time and quality. As a multi-objective genetic algorithm, this model embarked on quantifying quality in a bid to optimize it in construction projects. Zhang et al. (2006) used particle swarm optimization algorithm to explore Resource Constrained Project Scheduling Problem (RCPSP) to minimize project time. Tareghian and Taheri (2007) employed electromagnetic meta-heuristic algorithm to minimize total project cost and maximize project quality. The application of the method was studied on a case study with 19900 activities and the results were acceptable. Afshar et al. (2007), in a bid to balance cost, time and quality, employed ant colony optimization algorithm. This model was also able to balance cost and time without taking quality into consideration. In a bid to balance quality, time 
and cost which are in conflict with each other, Iranmanesh et al. (2008) applied a meta-heuristic algorithm which is a version of the genetic algorithm called FastPGA to solve multi-objective problems. Wang and Feng (2008) employed hierarchical particle swarm optimization algorithm to balance time, cost and quality. The aforementioned researchers considered mathematical models for cost-time and quality separately and provided a multi-objective optimization model for cost-time and quality which was formed of giving weight to each objective function. Kim et al. (2012) presented a mixed integer linear programming model to consider potential quality cost in time-cost trade off problem. Their model employed a coefficient, " $\alpha$ ", to consider activity non-conformance risk. Shahsavari Pour et al. (2012) employed linguistic variables in order to create a balance among cost, quality and time in projects. They studied uncertainties resulted from project quality by employing fuzzy logic and linguistic variables. They also employed the meta-heuristic algorithm Niche Hybrid Genetic Algorithm (NHGA) in order to solve the model. Ebrahimnezhad (2013) studied the balancing of time, cost and quality in CPM network by employing fuzzy logic and genetic algorithm. Afterwards, a case study was conducted in the domain of oil industry and the performance of the proposed mode and algorithm was tested. The results obtained in the study were acceptable. Ke and Ma (2014) presented three kinds of time-cost trade off models. In their models, the project environment was described through the introduction of random fuzzy theory. In the above-mentioned studies, the cost of quality that are comprised of cost of conformance and non-conformance of the deliverables have not been taken into consideration simultaneously. Furthermore, in all the studies conducted so far the project risk impact has not been taken into consideration either. And this is the key factor that can impact the project fate to a great extent. In the present study, we consider the aforementioned factors that have not been explored so far by presenting a comprehensive model.

\section{The proposed model}

In CPM calculations, we assume that all the activities are achievable during the determined duration. But there are some cases in which, based on the client's requirement or the organization's policies, there is a need to finish the project before the planned date. The following shows the sets, parameters and the variables defined in the presented model.

\section{Sets}

E The set of all activities

$S \quad$ The set of activities that need preventive action based on the project manager's view

\section{Decision-making variables}

$y_{i g} \quad$ The time reduced form the $i g^{\text {th }}$ activity

The binary variable in a way that if the quality of the $i g^{\text {th }}$ activity is lower than the

$w_{i g} \quad$ level determined by the project manager, the activity needs preventive action, otherwise, it does not.

$x_{i} \quad$ The time of finishing the $i^{\text {th }}$ node

The binary variable in a way that if the quality of the $i g^{\text {th }}$ activity is lower than the

$w w_{i g} \quad$ level determined by the project manager, the activity needs corrective action, otherwise, it does not.

\section{Parameters}

$c y_{i g} \quad$ The cost of each unit of the reduction of $i g^{\text {th }}$ activity

$c w_{i g} \quad$ The cost of preventive action for the conformance of the variable of $i g^{\text {th }}$ activity

$p_{i g} \quad$ The non-conformance probability of the deliverable of $i g^{\text {th }}$ activity 
$c d_{i g} \quad$ The non-conformance cost of the deliverable of $i g^{\text {th }}$ activity

$Q_{i g} \quad$ The quality threshold determined by the project manager for doing corrective action

$\lambda_{\text {igja }} \quad$ This integer parameter is -1 for opportunity and +1 for threat

$p b_{i g j a} \quad$ The probability of the occurrence of the risk ja in the activity $i g$

$C I_{i g j a} \quad$ The impact (cost) of risk $j a$ on the activity $i g$

$p b_{i g j^{\prime} a} \quad$ The probability of the occurrence of the risk $j^{\prime} a$ in the activity $i g$

$C I_{i g j a} \quad$ The impact (cost) of risk $j^{\prime} a$ on the activity $i g$

$d_{i g} \quad$ The duration of doing the activity $i g$

$c_{\text {direct }} \quad$ Direct cost of project

$c_{v} \quad$ The overhead cost of each unit of the time of doing the project

$M \quad$ A big number

$u_{i g} \quad$ The permitted limit of the time reduction of the activity $i g$

$Q_{i g}^{\prime} \quad$ The quality threshold, determined by the project manager, to do preventive action

The mathematical model presented to solve the problem is shown in the following model. The Eqs. (28 ) indicate this objective and the Eqs. (9-17) show the constraints of the model.

Objective function:

$$
\begin{aligned}
& f_{1}=\sum_{i} \sum_{g}\left(y_{i g} \times c y_{i g}\right) \\
& f_{2}=\sum_{i^{\prime}} \sum_{g}\left(w_{i g} \times c w_{i g}\right) \\
& f_{3}=\sum_{i^{\prime \prime}} \sum_{g}\left(p_{i g} \times c d_{i g} \times w w_{i g}\right) \\
& f_{4}=\sum_{i} \sum_{g} \sum_{j} \sum_{a} \lambda_{i g j a}\left[\left(p b_{i g j a}+\left(1-p b_{i g j a}\right) \times \frac{y_{i g}}{d_{i g}}\right) \times C I_{i g j a}\right] \quad i g \in E \\
& f_{5}=\sum_{i} \sum_{g} \sum_{j} \sum_{a} \lambda_{i g j a}\left[\left(p b_{i g j a}-\left(p b_{i g j a} \times \frac{y_{i g}}{d_{i g}}\right)\right) \times C I_{i g j a}\right] \quad i g \in E \\
& f_{6}=c_{\text {direct }}+c_{\max } \times c_{v} \\
& \min z=f_{1}+f_{2}+f_{3}+f_{4}+f_{5}+f_{6}
\end{aligned}
$$


subject to.

$$
\begin{array}{ll}
x_{1}=0 & \forall i g \in E \\
x_{g} \geq x_{i}+d_{i g}-y_{i g} & \\
x_{n}=c_{\max } & \forall i g \in S \\
Q_{i g}^{\prime} \leq\left(1-\frac{y_{i g}}{d_{i g}}\right)+w_{i g} \times M & \\
Q_{i g} \leq\left(1-\frac{y_{i g}}{d_{i g}}\right)+w w_{i g} \times M & \forall i g \in E \\
y_{i g} \leq u_{i g} & \forall i g \in E \\
y_{i g} \geq 0 & \forall i g \in E \\
w_{i g}=\{0,1\} & \forall i g \in E \\
w w_{i g}=\{0,1\} & \forall i g \in E
\end{array}
$$

In order to achieve the determined time, some activities need to be completed before the determined times. Thus, the present study aims to achieve the intended time by spending the minimum required cost and by taking quality and project risks into account. The Eqs. (2-7) express these objectives. The objective function $f_{1}$ in the Eq. (2) indicates the cost of resource increase per reduction of activity time. According to the project manager's view, preventive action can be done only in some activities. The objective function in the Eq. (3) represents the cost of preventive action for the activities that are determined by the project team.

The objective function $f_{3}$ in the Eq. (4) represents the cost of non-conformance of the deliverables in the project which is considered to belong to project quality costs.

The objective function $f_{4}$ in the Eq. (5) represents activities whose risk of occurrence is increased with the decrease of activity time. The probability of occurrence of this type of risk has an inverse relationship with the activity time. The objective function $f_{5}$ in the Eq. (6) represents activities whose risk of occurrence is reduced with the decrease of activity time. The probability of occurrence of this type of risk has a direct relationship with the activity time.

The objective function $f_{6}$ in the Eq. (7) includes the direct and indirect cost of the project implementation. Therefore, the aim of the problem explored is minimization of the above-mentioned costs, as shown in Eq. (8).

The sets of Eqs. (9-11) represent the time of occurrence of each node for archiving the delivery time in the CPM network. Supposing that the time of the start of the project is the moment zero and the aim of finishing the project is in the intended time, the aforementioned set of constraints calculates the time of ending each node in the group in proportion to the prerequisite Equations defined in the problem.

The sets of Eqs. (12-13) are aimed at considering the quality costs based in the project team's view. The Eq. (12) suggests that if the quality of the activity $i j$ is reduced from the quality level determined by the project manager (which is represented by $Q_{i g}^{\prime}$ in the mode) after the crashing, the binary variable 
$w_{i g}$ will be in the constraint of one and thus, the activity will be subjected the cost of conformance of deliverables. The Eq. (13) suggests that if the quality of the activity $i j$ is reduced from the quality level determined by the project manager (which is represented by $Q_{i g}$ in the mode) after the crashing, the binary variable $w w_{i g}$ will be in the constraint of one and thus, the activity will be subjected the cost of non-conformance of deliverables. Given the lack of too much reduction in activity time, the Eq. (14) determines the maximum reducible time for each activity. The sets of Eqs. (15), (16) and (17) are the general constraints of the problem.

\section{Numerical example}

In order to elucidate the topic, a numerical example is presented. Consider a project with 6 activities whose AOA network is as Fig. 2.

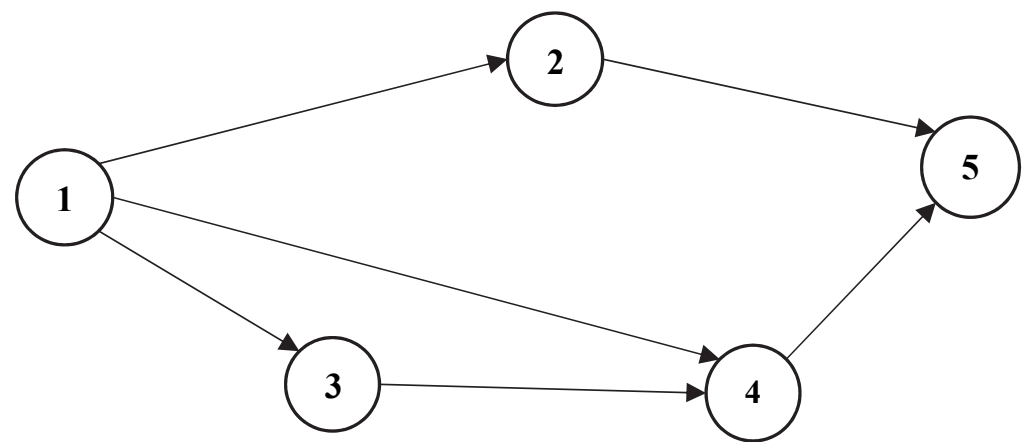

Fig. 2. The AOA network of the project

The initial information related to the activities and the quality of each activity has been collected in Table 2 by the project team:

Table 2

The project's initial inputs

\begin{tabular}{ccccccccc}
\hline Activity index & $\boldsymbol{d}_{\boldsymbol{i} \boldsymbol{g}}$ & $\boldsymbol{u}_{\boldsymbol{i} \boldsymbol{g}}$ & $\boldsymbol{c} \boldsymbol{y}_{\boldsymbol{i} \boldsymbol{g}}$ & $\boldsymbol{p}_{\boldsymbol{i} \boldsymbol{g}}$ & $\boldsymbol{c d}_{\boldsymbol{i} \boldsymbol{g}}$ & $\boldsymbol{c w}_{\boldsymbol{i} \boldsymbol{g}}$ & $\boldsymbol{Q}_{\boldsymbol{i} \boldsymbol{g}}$ & $\boldsymbol{Q}_{\boldsymbol{i} \boldsymbol{g}}$ \\
\hline $\mathbf{1}-\mathbf{2}$ & 6 & 4 & 30 & $20 \%$ & 1000 & 200 & $80 \%$ & $100 \%$ \\
$\mathbf{1}-\mathbf{3}$ & 3 & 2 & 40 & $50 \%$ & 800 & 120 & $70 \%$ & $95 \%$ \\
$\mathbf{1}-\mathbf{4}$ & 6 & 3 & 25 & $30 \%$ & 1200 & 300 & $85 \%$ & $100 \%$ \\
$\mathbf{2}-\mathbf{5}$ & 4 & 2 & 50 & $25 \%$ & 740 & 80 & $90 \%$ & $100 \%$ \\
$\mathbf{3}-\mathbf{4}$ & 4 & 2 & 45 & $60 \%$ & 950 & 130 & $65 \%$ & $80 \%$ \\
$\mathbf{4}-\mathbf{5}$ & 5 & 3 & 55 & $15 \%$ & 400 & 50 & $75 \%$ & $85 \%$ \\
\hline
\end{tabular}

The impact and probability related to the risks of the activities are presented in Table 3.

Table 3

The risk of activity

\begin{tabular}{cccc}
\hline Activity index & Type of risk & $\boldsymbol{p b}_{i g j a}$ & $\boldsymbol{C I}_{i g j a}$ \\
\hline $\mathbf{1}-\mathbf{2}$ & Threat & $20 \%$ & 1000 \\
$\mathbf{1}-\mathbf{3}$ & - & - & - \\
$\mathbf{1}-\mathbf{4}$ & - & - & - \\
$\mathbf{2}-\mathbf{5}$ & Opportunity & $40 \%$ & 1600 \\
$\mathbf{3}-\mathbf{4}$ & - & - & - \\
$\mathbf{4}-\mathbf{5}$ & - & - & - \\
\hline
\end{tabular}

Considering the collected information and section 3, we have the Eq. (18): 
Objective function:

$$
\begin{aligned}
& \min Z=30 y_{12}+40 y_{13}+25 y_{14}+50 y_{25}+45 y_{34}+55 y_{54}+200 w_{12}+120 w_{13}+300 w_{14}+80 w_{25} \\
& +130 w_{34}+50 w_{45}+(0.2 \times 1000 \times w w 12)+\left(0.5 \times 800 \times w w_{13}\right)+\left(0.3 \times 1200 \times w w_{14}\right)+(0.25 \times \\
& \left.740 \times w w_{25}\right)+\left(0.6 \times 950 \times w w_{34}\right)+\left(0.15 \times 400 \times w w_{45}\right)+\left(0.2+(1-0.2) \times \frac{y_{12}}{6}\right) \times 1000-(0.4 \\
& \left.+(1-0.4) \times \frac{y_{25}}{4}\right) \times 1600+\left(1500+120 \times x_{5}\right)
\end{aligned}
$$

subject to.

$$
\begin{array}{lll}
x_{1}=0 & 1 \leq\left(1-\frac{y_{12}}{6}\right)+w_{12} \times M & 0.80 \leq\left(1-\frac{y_{12}}{6}\right)+w w_{12} \times M \\
x_{2} \geq x_{1}+6-y_{12} & 0.95 \leq\left(1-\frac{y_{13}}{3}\right)+w_{13} \times M & 0.70 \leq\left(1-\frac{y_{13}}{3}\right)+w w_{13} \times M \\
x_{3} \geq x_{1}+3-y_{13} & 1 \leq\left(1-\frac{y_{14}}{6}\right)+w_{14} \times M & 0.85 \leq\left(1-\frac{y_{14}}{6}\right)+w w_{14} \times M \\
x_{4} \geq x_{1}+6-y_{14} & 1 \leq\left(1-\frac{y_{25}}{4}\right)+w_{25} \times M & 0.90 \leq\left(1-\frac{y_{25}}{4}\right)+w w_{25} \times M \\
x_{4} \geq x_{3}+4-y_{34} & 0.80 \leq\left(1-\frac{y_{34}}{4}\right)+w_{34} \times M & 0.65 \leq\left(1-\frac{y_{34}}{4}\right)+w w_{34} \times M \\
x_{5} \geq x_{2}+4-y_{25} & & \\
x_{5} \geq x_{4}+5-y_{45} & 0.85 \leq\left(1-\frac{y_{45}}{5}\right)+w_{45} \times M & 0.75 \leq\left(1-\frac{y_{45}}{5}\right)+w w_{45} \times M \\
x_{5}=8 &
\end{array}
$$

$\begin{array}{llll}y_{12} \leq 4 & y_{12} \geq 0 & w_{12} \in\{0,1\} & w w_{12} \in\{0,1\} \\ y_{13} \leq 2 & y_{13} \geq 0 & w_{13} \in\{0,1\} & w w_{13} \in\{0,1\} \\ y_{14} \leq 3 & y_{14} \geq 0 & w_{14} \in\{0,1\} & w w_{14} \in\{0,1\} \\ y_{25} \leq 2 & y_{25} \geq 0 & w_{25} \in\{0,1\} & w w_{25} \in\{0,1\} \\ y_{34} \leq 2 & y_{34} \geq 0 & w_{34} \in\{0,1\} & w w_{34} \in\{0,1\} \\ y_{45} \leq 3 & y_{45} \geq 0 & w_{45} \in\{0,1\} & w w_{45} \in\{0,1\}\end{array}$

The above model is solved by the LINGO software version 11.0 and the optimal solutions are presented as follows,

$$
\begin{aligned}
& y_{12}=0.0, y_{13}=0.9, y_{14}=0.0, y_{25}=2.0, y_{34}=0.1, y_{45}=3.0, \\
& w_{12}=0, w_{13}=1, w_{14}=0, w_{25}=1, w_{34}=0, w_{45}=1 \\
& w w_{13}=0, w w_{14}=0, w w_{25}=1, w w_{34}=0, w_{45}=1
\end{aligned}
$$


According to the results, in order to achieve this project's deadline, the duration of the activities 1-3, 2-5, 3-4 and 4-5 is reduced, by considering the crashing costs. Activities 1-3, 2-5 and 4-5 need preventive actions and activities 2-5 and 4-5 may require corrective action in the future.

\section{Conclusion}

A project manager's main work is to finish the project based on the determined objectives. In most of the cases, after the project team prepare the initial project schedule, it is revealed that there is a need for plan duration reduction. The present study employed integer programming in order to do an optimal crashing of project activities. Efforts were made to consider most of the factors involved in doing a project in order to make the model more applicable and real. The modelling of quality costs can be a useful tool for consideration of project quality in order to meet the needs of key stakeholders of the project. Project risk is an uncertain event or condition that, if it occurs, has a positive or negative effect on one or more project objectives such as scope, schedule, cost, and quality (Project Management Institute., 2009). As a result, the failure to consider project risks will lead to the decreased project success prospect. The presented model, by completely taking project risks into consideration, will highly reduce the uncertainties. The model can be examined in uncertainty conditions in future studies.

\section{References}

Afshar, A., Kavek, A., \& Shoghli, O. (2007). Multi-Objective Optimization of Time-Cost-Quality Using Multi-Colony Ant Algorithm. Asian Journal of Civil Engineering (Building and Housing), 8(2), 113-124.

Babu, A. J., \& Suresh, N. (1996). Theory and Methodology Project management with time, cost, and quality considerations. European Journal of Operational Research, 88(7), 320-327.

Kiran, D.R. (2017). Cost of Quality, In Total Quality Management, Butterworth-Heinemann, pp. 99111.

Ebrahimnezhad, S., Ahmadi,V., \& Javanshir, H. (2013). Time-Cost-Quality Trade-off in a CPM1 Network Using Fuzzy Logic and Genetic Algorithm. International Journal of Industrial Engineering \& Production Management, 24(3), 361-376.

El-Rayes, K., \& Kandil, A. (2005). Time-cost-quality trade-off analysis for highway construction. Journal of construction Engineering and Management, 131(4), 477-486.

Lester, A. (2006). Project management, planning and control: managing engineering, construction and manufacturing projects to PMI, APM and BSI standards. Butterworth-Heinemann.

Feng, C. (1997). Using GA to solve construction time cost Trade off Problem. Journal of Computing in Civil Engineering, 11(3), 184-189.

Feng, C., Liu, L., \& Burns, S.A. (2000). Stochastic Construction Time-Cost Trade-Off Analysis. Journal of Computing in Civil Engineering, 14(2), 117-126.

Iranmanesh, H., Skandari, M.R., \& Allahverdilloo, M. (2008). Finding Pareto Optimal Front for the Multi-Mode Time, Cost Quality Trade-off in Project Scheduling. International Journal of Computer and Information Engineering, 2(2), 118-122.

$\mathrm{Ke}, \mathrm{H}, \&$ Ma. J. (2014). Modeling project time-cost trade-off in fuzzy random environment. Applied Soft Computing, 19, 80-85.

Kelly, J.E. (1961) Critical Path Planning and Scheduling: Mathematical Basis. Operational Research Journal, 9(3), 167-169.

Khang, D.B., \& Myint, Y.M. (1999). Time, cost and quality trade-off in project management: A case study. International Journal of Project Management, 17(4), 249-256.

Kim, J., Kang, C., \& Hwang, I. (2012). A practical approach to project scheduling: considering the potential quality loss cost in the time cost tradeoff problem. International Journal of Project Management, 30(2), 264-272.

Leu, L., Burns, S., \& Feng, C. (2005). Construction time- cost trade-off analysis using LP/IP hybrid model. Journal of Construction Engineering Management, 121(4), 446-454. 
Project Management Institute. (2009). PRACTICE STANDARD FOR PROJECT RISK MANAGEMENT (PMBOK ${ }^{\circledR}$ Guide) Fourth Edition. Newtown Square, PA: Author.

Project Management Institute. (2011). PRACTICE STANDARD FOR SCHEDULING (PMBOK ® Guide) Second Edition. Newtown Square, PA: Author.

Project Management Institute. (2013). A Guide to the Project Management Body of Knowledge (PMBOK ${ }^{\circledR}$ Guide) Fifth Edition. Newtown Square, PA: Author.

Sakellaropoulos, S., \& Chassiakos, A. P. (2004). Project time - cost analysis under generalised precedence relations. Advances in Engineering Software, 35(10-11), 715-724.

Shahsavari Pour, N, Modarres, M \& Tavakkoli-Moghaddam, R. (2012). Time-cost-quality trade-off in project scheduling with linguistic variables. World Applied Sciences Journal, 18(3), 404-413.

Tareghian, H.R., \& Taheri, S.H.R. (2007). A Solution Procedure for the Discrete Time, Cost and Quality Trade off Problem using Electromagnetic Scatter Search. Applied Mathematics and Computation, 182(1), 305-312.

Wang, W., \& Feng, Q. (2008). Multi-objective Optimization in Construction Project Based on a Hierarchical Subpopulation Particle Swarm Optimization Algorithm. Proceeding of Second International Symposium on Intelligent Information Technology Application, Published in: Proceeding IITA, 1(8), 746-750.

Zhang, H., Li, H., \& Tam, C.M. (2006). Particle Swarm Optimization for Resource-Constrained Project Scheduling. International Journal of Project Management, 24(1), 83-92.

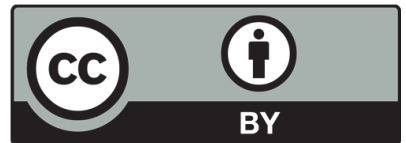

(C) 2017 by the authors; licensee Growing Science, Canada. This is an open access article distributed under the terms and conditions of the Creative Commons Attribution (CC-BY) license (http://creativecommons.org/licenses/by/4.0/). 